\title{
Aktif yeşil alan olanaklarının verimlilik açısından değerlendirilmesi: Çanakkale örneği
}

\author{
Assessment in terms efficiency of active green space facilities: Çanakkale example
}

\section{Yavuz ALKAN}

Lapseki Meslek Yüksekokulu, Çanakkale Onsekiz Mart Üniversitesi, Çanakkale, Türkiye

\section{Eser Bilgisi / Article Info}

Araştırma makalesi / Research article

DOI: $10.17474 /$ artvinofd.594804

Sorumlu yazar / Corresponding author

Yavuz ALKAN

e-mail: yalkan58@comu.edu.tr

Geliş tarihi / Received

21.06.2019

Düzeltme tarihi / Received in revised form

30.11.2019

Kabul Tarihi/Accepted

18.12.2019

Elektronik erişim / Online available

12.03.2020

\section{Anahtar kelimeler:}

Aktif Yeşil Alanlar

Verimlilik

Planlama

Çanakkale

\section{Keywords:}

Active green spaces

Efficiency

Planning

Çanakkale

\begin{abstract}
Özet
Bu çalışma ile son yıllarda hızla değişen ve gelişen Çanakkale kentsel alanındaki mevcut aktif yeşil alanlardan mahalle parkı, çocuk oyun alanı ve spor alanı türlerinin verimlilikleri araştırılmıştır. Bunun için merkez mahalleler kapsamında nüfus grupları ve sayıları ile her mahalle için belirlenen mahalle parkı, çocuk oyun alanı ve spor alanı kullanım alanları büyüklük ve kullanıcıya uzaklık gibi niceliklerle ilişkilendirilmiştir. Bu kapsamda merkez mahallelerin yeşil alan endeks değerlerinin 16.46 ile 100; verimlilik yeşil alan değerlerinin ise 45.32 ile 65.62 arasında dağılım gösterdiği tespit edilmiştir. Yeşil alan endeks değeri 100 olan Namık Kemal Mahallesi'nin verimlilik yeşil alan değeri 51.25'a gerilemiştir. Bunun gibi Barbaros (56.41) ve Esenler Mahallesi'nin (65.62) verimlilik yeşil alan endeks değerleri de gerilemiştir. Bunun tersine, yeşil alan endeks değerleri 44.51, 18.07, 43.18, 16.46 olan aynı sırayla Cevatpaşa, Kemalpaşa, İsmetpaşa ve Fevzipaşa Mahallelerinin verimlilik yeşil alan değerlerinin ise, $54.22,45.55$ ve 52.20, 45.32 olarak arttıkları görülmüştür. Bu durum, bu mahallelerdeki nüfusun, rekreasyonel gereksinimlerini diğer mahallelerdeki yeşil alan olanaklarıyla karşıladıklarını göstermektedir. Dolayısıyla, dengeli dağıııma sahip olmayan yeşil alanların kent genelinde yararlanma yüzdeleri, yeşil alan verimlilik değeri azalan yönde ise fazla, artan yönde ise az olmaktadır. Buradan bir kentteki bölgesel yeşil alanların sayı, alan ve olanaklar çerçevesinde fazla olmalarının verimlilikle ilişkilendirilemeyeceği sonucu çıkmaktadır. Sonuç olarak kent dokusunda önemli bir yere sahip olan aktif yeşil alan türlerinin planlanmasında nüfus grupları ve gereksinimlerine bağlı kalınması öncelikli olmalıdır.
\end{abstract}

\begin{abstract}
This study researched the efficiency of neighborhood park, children's playground and sports field types from active green spaces present in the Çanakkale urban area. For this purpose, population groups and numbers within the central neighborhoods and the neighborhood park, children's playground and sports field usage areas determined for each neighborhood were associated with quantities such as size and distance to the user. Within this scope, of the green space index values in central neighborhoods were between 16.46 and 100; with efficient green space values distributed from 45.32 to 65.62 . Namık Kemal Neighborhood with green space index value of 100 had an efficient green space area value of only 51.25. Similar to this, Barbaros (56.41) and Esenler Neighborhoods (65.62) had regression of efficient green space area values. Contrary to this, Cevatpaşa, Kemalpaşa, İsmetpaşa and Fevzipaşa Neighborhoods with green space index values of 44.51, 18.07, 43.18 and 16.46, respectively, were observed to have increases in efficient green space values of 54.22, 45.55, 52.20 and 45.32 respectively. This situation shows the population in these neighborhoods fulfilled their recreational requirements in green space facilities in other neighborhoods. As a result, the inequality in distribution of benefit percentages for green areas in the city in general is greater in terms of reducing the efficient green space value, and low in terms of increasing it. From here it is understood that the excess of regional green spaces in a city within the framework of number, area and amenities cannot be associated with efficiency. As a result, it should be a priority to depend on population groups and requirements in planning active green space species that have an important place in urban tissue.
\end{abstract}

\section{Giriş}

Dış mekan kullanımları arasında en yaygın olanı aktif yeşil alanlar olup, özellikle kentsel dokuda öne çıkanları mahalle parkı, çocuk oyun alanı ve spor alanı türleridir. Aktif yeşil alanlar toplumun kendini ruhsal ve psikolojik açıdan yenilemesi (rekreasyon) ile öne çıkan yapılardır. Bu yönüyle kent dinamiğinde önemli bir paya sahiptirler (Sağlık ve ark. 2016, Akpınar 2019). Ancak aktif yeşil alanlar, kent dokusundaki donatıları, sayıları ve lokalizasyonları gereği, kullanım amaçlarını, verimliliklerini ve kullanıcı memnuniyetlerini farklı kılabilmektedir (Alkan ve ark. 2016). Mahalle ölçeğinde nüfus gruplarının dikkate alınmadan planlanması ile ortaya çıkan yetersiz alan ve sayıdaki aktif yeşil alanlar, söz konusu mahalle nüfusunu diğer mahallelerdeki aktif yeşil alanların kullanımına yönlendirerek bu alanların verimliliğinin düşmesine yol açabilmektedir (Alkan ve 
Uslu 2016, Anonim 2016). Ayrıca, kişi başına ihtiyaçtan fazla aktif yeşil alana sahip bu mahallelerde fırsatçıların, alanı, çocuk istismarı, madde bağımlılığı, kapkaç gibi istenmeyen sosyal olayların yaşanmasında kullanmasına da neden olabilmektedir (Anonim 2016). UNICEF'in Türkiye genelinde yaptığı anket çalışmasında yaşanılan çevre, mahalle ve sokakların, çocukların istismarına zemin hazırlayan bir ortam olduğunu ortaya koymuştur (Anonim 2010). Benzer şekilde istatistikler çocuk istismarı, cinayet olayları, madde bağımlılığı gibi olayların zamana bağlı olarak arttığını da göstermektedir (Anonim 2014a, Anonim 2017a, Anonim 2017b, Anonim 2018). Nüfus yoğunluğunun fazla olduğu kentsel alanlarda AYA'ların da bu tür sosyal olaylarda payının olduğu yadsınamaz. Dolayısıyla bu durum kent dokusunda yer alan merkez mahallelerdeki aktif yeşil alanların nüfus dağılımına ve çeşitliliğine bağlı olarak yeterli sayıda ve alanda planlanmasının gerekliliğini öne çıkarmaktadır. Öyle ki, kentsel yaşam kalitesinin belirleyicisi olan peyzaj donatı alanları ve aktif yeşil alanlar gibi "fiziksel karakteristikler" sahip olduğu nüfus ve içerdiği işlevsel/estetik alanlar bakımından kentsel ölçekte önemli bir yere sahiptir (Cohen 1996, Gangloff 1996, Torunoğlu 1997, Geray 1998, Brown ve ark. 1998, Bolund ve Hunhammar 1999, Willis ve ark. 2001, Çukurçayır 2002, Jim 2004, Alkan ve Uzun 2016). Söz konusu yeşil alanların kullanım değerini araştırmak, kendi başına yeterli yaşam alanı oluşturması ile büyük önem taşımaktadır (Payne 2009, Göçer ve ark. 2018). Kentsel yaşam kalitesinin değerini belirlemek adına ölçüt olarak son yıllarda "Sürdürülebilir Ekonomik Refah Endeksi", "Rekreasyon Olanakları Endeksi" gibi endeks değerlerinin farklı bileşenleri ilişkilendirilerek tanımlanan sayısal ifadeler kullanılmaktadır (English ve Cordell 1993, Brown ve ark. 1998, Gilliland ve ark. 2006). Bunun için de yeşil alanların planlama ve tasarımlarında öne çıkan unsurların başında kişi başına yeşil alan miktarları, nüfus grupları ve projeksiyonları gelmektedir. Nüfus farklılıkları ölçeğinde yeter sayıda/alanda, güvenli, hedef kitle odaklı gerekli donatıların olduğu mahalle parkı, çocuk oyun alanı ve spor alanı gibi aktif yeşil alanların kent dokusundaki önemi yadsınamaz. Yeşil alanlar, miktar ve kalite bakımından nüfus artışına paralel artış gösteren plansız ve kontrolsüz yapılaşmalara karşın artarak ilerleyen azalma eğilimindedir. (Alkan ve ark. 2016). Çalışma alanı olan Çanakkale merkez mahallelerinde ağırlıklı olarak özellikle nüfus fazlalığı olan mahallelerde aktif yeşil alanların sayıca az ve donatı yetersizliği söz konusuyken, nüfus yoğunluğu az olan mahallelerde ise sayıca ve donatıca fazla olan aktif yeşil alanların olması önemli bir sorun olarak karşımıza çıkmaktadır. Kentlinin yaşam kalitesinde etkili olan bu durum sorunu daha da önemli kılmaktadır (Külekçi ve Irmak 2019). Çanakkale merkez mahallelerinde, nüfus dağılımlarını dikkate alarak, kişi başına düşen yeşil alana bağlı aktif yeşil alan planlama ve tasarımlarına yer veren bu çalışmanın bu sorunu gidermek adına önemli bir rol alacağı düşünülmektedir. Bu çalışma ile son yıllarda hızla değişen ve gelişen Çanakkale kentsel alanındaki mahalle parkları, çocuk oyun alanları ve spor alanları potansiyelinde verimliliklerinin araştırılması amaçlanmıştır.

\section{MATERYAL VE YÖNTEM}

Çalışma, coğrafi olarak Türkiye'nin kuzeybatısında, $25^{\circ}$ $35^{\prime}$ ve $27^{\circ} 45^{\prime}$ doğu boylamları ile $39^{\circ} 30^{\prime}$ ve $40^{\circ} 42^{\prime}$ kuzey enlemleri arasında konumlanan Çanakkale kentsel alanındaki merkez mahalleleri; Barbaros, Cevatpaşa, Esenler, Fevzipaşa, İsmetpaşa, Kemalpaşa ve Namık Kemal mahallelerinde yürütülmüştür. Söz konusu mahallelerde yer alan aktif yeşil alanlara ait verilere ulaşmak için arazi ve ofis çalışmaları koordineli gerçekleştirilmiş, yerinde yapılan arazi çalışması gözlem ve tespitlerle ofis çalışmasından elde edilen Uygulama İmar Planı, hava fotoğrafı ve AutoCAD ölçümleri, birlikte değerlendirilmiştir (Şekil 1).

Mahalle nüfusları, Adrese Dayalı Nüfus Kayıt Sistemi verilerinden (Anonim 2017c), aktif yeşil alan türleri ile alanları ise 1/1000 ölçekli Uygulama İmar Planı'ndan elde edilmiştir. Bu bilgiler her aktif yeşil alan türü için mahalle bazında kişi başına düşen alanların hesaplanmasında kullanılmıştır. Öncelikle her mahallede bulunan toplam mahalle parkı ve spor alanı o mahallenin 13 yaş üstü nüfusuna oranlanarak kişi başına düşen alanlar bulunmuş, aynı şekilde çocuk oyun alanı için, kişi başına düşen alan, 0-12 yaş nüfusuna oranlanarak elde edilmiştir. Mahalle ölçeğinde; her aktif yeşil alan türü için kişi başına elde edilen değerlerin en yükseği 100 kabul edilmiş, diğer değerler bu değere oranlanarak her aktif yeşil alan türü için endeks değerleri hesaplanmıştır. Daha sonra mahalle düzeyindeki aktif yeşil alan endekslerinin aritmetik ortalaması alınmıştır. Her mahallenin "aktif yeşil alan olanakları seti endeksi" (AYAOSE), o mahallenin ortalama endeks değeri, mahalleler içindeki en yüksek ortalama endeks değerine oranlanıp 100 ile çarpılması sonucu elde edilmiştir. 


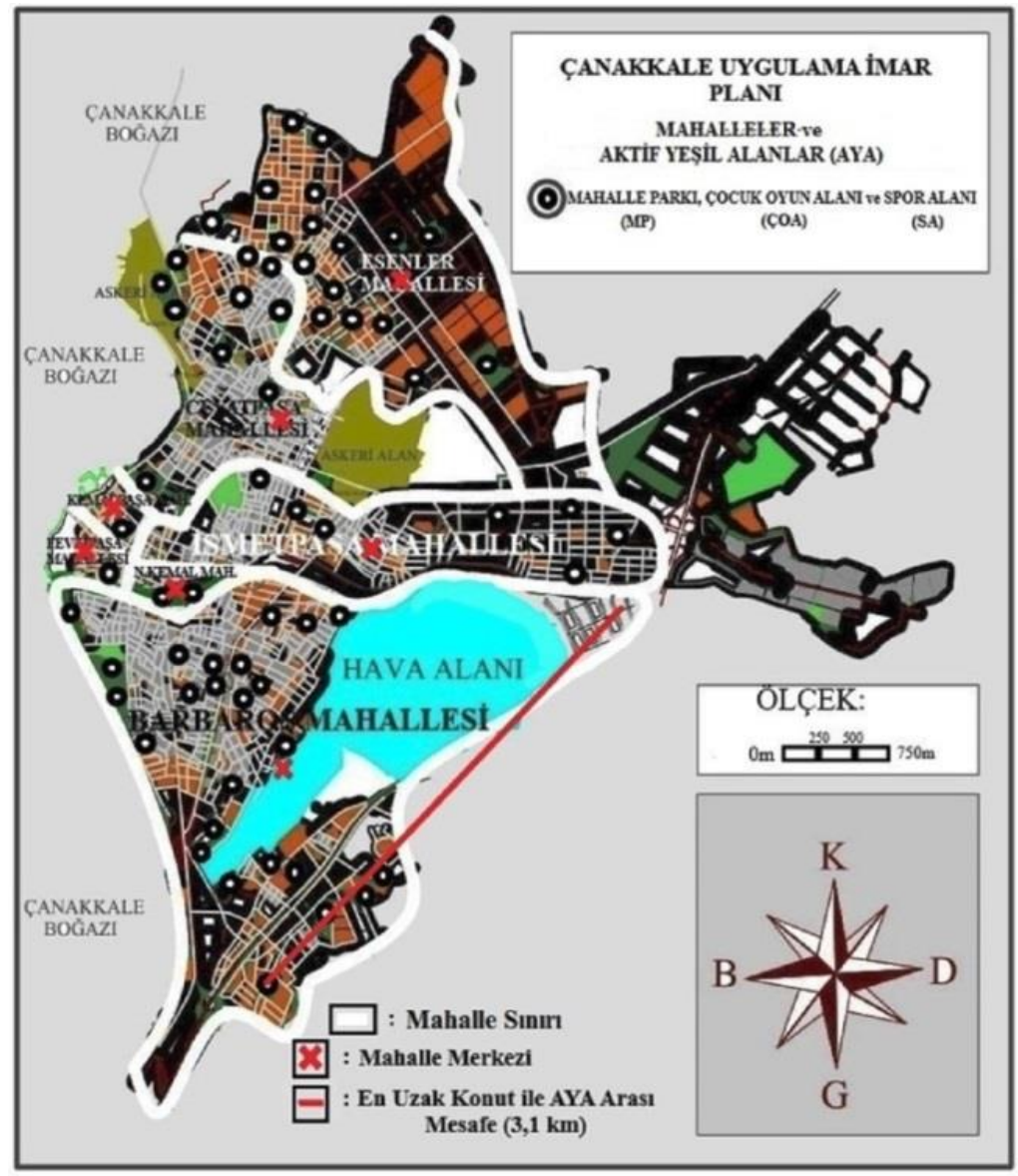

Şekil 1. Çanakkale lokalizasyonu ve merkez mahalle dağılımları ile aktif yeşil alanları (Anonim 2017d

AYAOSE değerleri mahalle aktif yeşil alan potansiyelinin göstergesidir. Bu değerlerin verimliliğinin belirlenmesi verimlilik değişme değerleri ile ilişkilendirilmesine bağlıdır. Verimlilik değişme değeri ise, aktif yeşil alan olanakları fazla olan mahallelerin, diğer mahallelerden gelen kullanıcı miktarı ile mevcut yoğunluğunun artması, dolayısıyla aktif yeşil alanların verimliliğinin azalması anlamına gelmektedir. Aktif yeşil alan olanaklarının verimlilik değişim (VD) değerlerinin hesaplanmasında mahalle merkezleri (sınırları kapsamında her mahalle için merkezi ağırlık noktası) arasındaki uzaklık $\left(U_{A B}\right)$, ile mahalleler düzeyinde herhangi bir aktif yeşil alanın (G) en uzak konuta olan mesafesi ( $\left.\mathrm{KU}_{\mathrm{GBA}}\right)(3,1 \mathrm{~km}$ ile beklentiye paralel olarak en geniş yüzölçümüne sahip olan Barbaros Mahallesi'nde tespit edilmiştir) belirleyici olmuştur (Şekil 1). Dolayısıyla, mahalleler $(A, B)$ arası verimlilik değişim değerleri (VD $\left.\mathrm{GAB}_{\mathrm{B}}\right)$ mahalle merkezleri arasındaki uzaklık (U $\left.U_{A B}\right) \quad 3,1$ km'den büyükse " 0 " kabul edilmiş, küçükse English ve Cordell (1993) tarafından belirtilen ve çalışmaya uyarlanan (Eşitlik 1) eşitliğiyle hesaplanmıştır.
$V D_{G A B}=1-\left(U_{A B} / K U_{G B A}\right)$ " $U_{A B}>K U_{G B A}$ ise" $V D_{G A B}=0$ " $U_{A B}$ $<K U_{G B A}$ ise" (Eşitlik 1) Eşitlikte yer alan sembollerin anlamları aşağıdadır.
$V D_{G A B}=$ Mahalleler $(\mathrm{A}, \mathrm{B})$ arasındaki aktif yeşil alan $(\mathrm{G})$ verimlilik değişim (VD) değeri, $U_{A B}=$ Mahalleler (A, B) arasındaki Uzaklık (U),
$K U_{G}=$ Herhangi bir aktif yeşil alanın (G) en uzak konuta (KU) mesafesi.

ABD Rekreasyon ve Parklar Yönetimi'nin (1989) geliştirdiği Verimli Rekreasyon Olanakları Seti (English ve Cordell, 1993) hesaplama yönteminin bu çalışmaya uyarlanarak (VAYAOS) hesaplanması, herhangi bir mahalle için, o mahallenin diğer mahallelerle olan verimlilik değişim değerleri birbirinden bağımsız tüm mahalleler için yeşil alan endeks değerleri ile çarpılarak toplanmış, daha sonra da yine o mahallenin ortalama verimlilik değişme değerine oranlanarak bulunmuştur (örnek hesaplama ilgili çizelgenin altında yer almaktadır). 


\section{BULGULAR VE TARTIŞMA}

Çalışmada uygulanan yöntem kapsamında üç farklı aşamada bulgular değerlendirilmiştir: Birinci aşamada Çanakkale merkez mahalleleri düzeyinde aktif yeşil alanların mahalle parkı, çocuk oyun alanı ve spor alanı türlerinde alanlarının belirlenmesine" çalışılmıştır. Bu doğrultuda, Çanakkale'nin 1/1000 ölçekli Uygulama İmar Planı́ndan elde edilen ve yapılan arazi çalışmaları ile teyit edilen aktif yeşil alanların nicelikleri ortaya konulmuştur (Çizelge 1).

Çizelge 1. Çanakkale kentsel alanındaki aktif yeşil alanların mahallelere göre dağılımı

\begin{tabular}{lcccc}
\hline \multirow{2}{*}{ Mahalleler } & MP & ÇOA & SA & Toplam \\
\cline { 2 - 5 } & $\left(\mathrm{m}^{2}\right)$ & $\left(\mathrm{m}^{2}\right)$ & $\left(\mathrm{m}^{2}\right)$ & $\left(\mathrm{m}^{2}\right)$ \\
\hline Barbaros & 113.235 & 16.500 & 3.250 & 132.985 \\
Cevatpaşa & 58.773 & 4.500 & 750 & 64.023 \\
Esenler & 92.294 & 14.500 & 3.000 & 109.794 \\
Kemalpaşa & 6.180 & 0 & 0 & 6.180 \\
İsmetpaşa & 47.958 & 3.500 & 500 & 51.958 \\
Fevzipaşa & 1.900 & 300 & 0 & 2.200 \\
Namık Kemal & 8.150 & 350 & 100 & 8.600 \\
\hline Toplam & 328.490 & 39.650 & 7.600 & 375.740 \\
\hline MP: Mahalle parkı; CSOA: Cocuk oyun alanı: SA: Spor alanı
\end{tabular}

MP: Mahalle parkı; ÇOA: Çocuk oyun alanı; SA: Spor alanı

Mahalle düzeyinde belirlenen bu büyüklükler o mahalle için Anonim (2017c)' den elde edilen nüfus miktarına bölünerek kişi başına aktif yeşil alan miktarları tespit edilmiştir (Çizelge 2, 3).

Çizelge 2. 31 Aralık 2017 tarihli adrese dayalı nüfus kayıt sistemi sonuçları/yaş grubuna göre mahalle nüfusları (Merkez-Çanakkale)

\begin{tabular}{lcc} 
Mahalleler & $\begin{array}{c}\text { 0-12 Yaş Grubu Nüfusu } \\
\text { (Anonim 2017c) }\end{array}$ & $\begin{array}{c}\text { 13 + Nüfusu } \\
\text { (Anonim 2017c) }\end{array}$ \\
\hline Barbaros & 8.105 & 47.220 \\
Cevatpaşa & 2.530 & 23.273 \\
Esenler & 4.979 & 22.966 \\
Kemalpaşa & 124 & 1.620 \\
İsmetpaşa & 2.183 & 16.720 \\
Fevzipaşa & 358 & 1.621 \\
Namık Kemal & 136 & 1.019 \\
\hline
\end{tabular}

Çanakkale kentsel alanında yer alan mahallelerde belirlenen türler yönünden kişi başına aktif yeşil alan miktarı $2.83 \mathrm{~m}^{2}$ olarak tespit edilmiştir. Bu değerin standardın (Anonim, 2014b) çok altında olması bakımından dikkat çekicidir. Mahalle düzeyinde her aktif yeşil alan türü için belirlenen kişi başına alanlar 100 ile çarpılmış, daha sonra kişi başına en yüksek miktara oranlanarak her mahalle için aktif yeşil alan endeks değerleri hesaplanmıştır. Buradan da her mahalle için ortalama endeks değerlerinin belirlenmesine gidilmiştir. Bunun için de yine mahalle düzeyinde her üç aktif yeşil alan türüne ait endeks değerlerinin ortalamaları alınmıştır. Elde edilen ortalama endeks değerleri Çizelge 3'te yer almaktadır.

Bu değerlere göre Namık Kemal Mahallesi'nin nüfus azlığından dolayı endeks değerinin Çanakkale kentselinde yer alan mahalleler kapsamında en büyük değere ulaştığı belirlenmiştir. Çocuk oyun ve spor alanları ise bütün mahallelerde nispeten düşük değerler almıştır. ikinci aşamada "aktif yeşil alanların verimlilik değişme değerleri" araştırılmıştır. Illk olarak mahalleler arasındaki doğrusal uzaklıkların $\left(\mathrm{U}_{\mathrm{AB}}\right), 0.41$ $\mathrm{km}$ ile $4.01 \mathrm{~km}$ arasında dağılım gösterdiği tespit edilmiştir (Çizelge 4). Ayrıca, $3.1 \mathrm{~km}$ ile en uzak mesafenin $\left(K_{G}\right)$ en büyük yüzölçümüne sahip Barbaros Mahallesi lokalizasyonunda olduğu tespit edilmiştir.

Tüm mahalleler potansiyelinde karşılıklı yeşil alan yararlanmalarındaki (verimliliklerinin) değişim miktarları, mahalleler arasındaki doğrusal mesafe 3,1 km'den büyükse "0" değeri verilmiş, küçükse (Eşitlik 1) eşitliği ile hesaplanmıştır (Çizelge 5). Üçüncü aşamada ise, "verimli aktif yeşil alan olanakları" her bir mahalle için, o mahallenin diğer mahallelerle arasındaki verimlilik değişim değerleri, ilgili mahallelerin yeşil alan endeks değerleri ile ayrı ayrı çarpılarak elde edilen değerlerin tümü toplanmış ve toplam da söz konusu mahallenin verimlilik değişim değerlerinin toplamına bölünerek elde edilmiştir (Çizelge 5, 6, 7). Merkez mahallelerin yeşil alan endeks değerlerinin geniş bir aralıkta (16.46 ile 100) dağılış gösterdiği, verimlilik yeşil alan değerlerinin 45.32 ve 65.62 gibi daha dar bir aralıkta dağılım gösterdiği tespit edilmiştir.

Yeşil alan endeks değeri 100 olan Namık Kemal Mahallesi'nin verimlilik yeşil alan değeri $51.25^{\prime} \mathrm{e}$ gerilemiştir. Benzer biçimde, Barbaros (56.41) ve Esenler Mahallesi'nin (65.62) verimlilik yeşil alan endeks değerleri de gerilemiştir. Böylece bu mahallelerdeki yeşil alanlar diğer mahalle sakinleri tarafından kullanılma eğilimine girerek bu mahallelerdeki yeşil alanların yararlanma oranlarını da düşürmektedir. 
Çizelge 3. Kişi başına aktif yeşil alanlar ve endeks değerleri

\begin{tabular}{|c|c|c|c|c|c|c|c|c|c|c|}
\hline \multirow[b]{2}{*}{ Mahalleler } & \multirow{2}{*}{$\begin{array}{c}\text { 0-12 } \\
\text { Yaş } \\
\text { Nüfus }\end{array}$} & \multirow[b]{2}{*}{$13+$ Nüfus } & \multirow[b]{2}{*}{ Toplam Nüfus } & \multicolumn{3}{|c|}{ Kişi Başına Değerler $\left(\mathrm{m}^{2}\right)$} & \multicolumn{3}{|c|}{ Endeks Değerleri } & \multirow{2}{*}{$\begin{array}{c}\text { Endex } \\
\text { Ortalama }\end{array}$} \\
\hline & & & & MP & ÇOA & SA & MP & ÇOA & SA & \\
\hline Barbaros & 8.105 & 47.220 & 55.325 & 2.40 & 2.04 & 0.07 & 29.98 & 69.96 & 52.94 & 50.96 \\
\hline Cevatpaşa & 2.530 & 23.273 & 25.803 & 2.53 & 1.78 & 0.03 & 31.57 & 61.12 & 24.79 & 39.16 \\
\hline Esenler & 4.979 & 22.966 & 27.945 & 4.02 & 2.91 & 0.13 & 50.23 & 100.08 & 100.48 & 83.60 \\
\hline Kemalpaşa & 124 & 1.620 & 1.744 & 3.81 & 0.00 & 0.00 & 47.69 & 0.00 & 0.00 & 15.90 \\
\hline İsmetpaşa & 2.183 & 16.720 & 18.903 & 2.87 & 1.60 & 0.03 & 35.85 & 55.10 & 23.00 & 37.98 \\
\hline Fevzipaşa & 358 & 1.621 & 1.979 & 1.17 & 0.84 & 0.00 & 14.65 & 28.80 & 0.00 & 14.48 \\
\hline Namık Kemal & 136 & 1.019 & 1.155 & 8.00 & 2.57 & 0.10 & 99.98 & 88.44 & 75.49 & 87.97 \\
\hline Toplam & 18.415 & 114.439 & 132.854 & 25 & 12 & 0 & & & & \\
\hline
\end{tabular}

Çizelge 4. Mahalle ağırlık merkezleri arasındaki doğrusal uzaklıklar

\begin{tabular}{lccccccc} 
Mahalleler & $\begin{array}{c}\text { Barbaros } \\
(\mathrm{km})\end{array}$ & $\begin{array}{c}\text { Cevatpaşa } \\
(\mathrm{km})\end{array}$ & $\begin{array}{c}\text { Esenler } \\
(\mathrm{km})\end{array}$ & $\begin{array}{c}\text { Kemalpaşa } \\
(\mathrm{km})\end{array}$ & $\begin{array}{c}\text { İsmetpaşa } \\
(\mathrm{km})\end{array}$ & $\begin{array}{c}\text { Fevzipaşa } \\
(\mathrm{km})\end{array}$ & $\begin{array}{c}\text { Namık Kemal } \\
(\mathrm{km})\end{array}$ \\
\hline Barbaros & 0.00 & 2.97 & 4.01 & 2.61 & 2.12 & 2.55 & 1.94 \\
Cevatpaşa & 2.97 & 0.00 & 1.16 & 2.02 & 1.14 & 1.65 & 1.66 \\
Esenler & 4.01 & 1.16 & 0.00 & 2.50 & 2.25 & 2.60 & 2.46 \\
Kemalpaşa & 2.61 & 2.02 & 2.50 & 0.00 & 2.29 & 0.41 & 0.70 \\
İsmetpaşa & 2.12 & 1.14 & 2.25 & 2.29 & 0.00 & 2.01 & 1.62 \\
Fevzipaşa & 2.55 & 1.65 & 2.60 & 0.41 & 2.01 & 0.00 & 0.64 \\
Namık Kemal & 1.94 & 1.66 & 2.46 & 0.70 & 1.62 & 0.64 & 0.00 \\
\hline
\end{tabular}

Çizelge 5. Mahalleler arasında aktif yeşil alan olanaklarındaki verimlilik değişim değerleri $\left(\mathrm{VD}_{\mathrm{GAB}}\right)$

\begin{tabular}{lcccccccc}
\hline Mahalleler & Barbaros & Cevatpaşa & Esenler & Kemalpaşa & İsmetpaşa & Fevzipaşa & N. Kemal & Toplam \\
\hline Barbaros & 1.00 & 0.04 & 0 & 0.16 & 0.32 & 0.18 & 0.37 & 2.07 \\
Cevatpaşa & 0.04 & 1.00 & 0.63 & 0.35 & 0.63 & 0.47 & 0.46 & 3.58 \\
Esenler & 0 & 0.63 & 1.00 & 0.19 & 0.27 & 0.16 & 0.21 & 2.46 \\
Kemalpaşa & 0.16 & 0.35 & 0.19 & 1.00 & 0.26 & 0.87 & 0.77 & 3.60 \\
İsmetpaşa & 0.32 & 0.63 & 0.27 & 0.26 & 1.00 & 0.35 & 0.48 & 3.31 \\
Fevzipaşa & 0.18 & 0.47 & 0.16 & 0.87 & 0.35 & 1.00 & 0.79 & 3.82 \\
Namık Kemal & 0.37 & 0.46 & 0.21 & 0.77 & 0.48 & 0.79 & 1.00 & 4.09 \\
AYAOSE & 57.93 & 44.51 & 95.03 & 18.07 & 43.18 & 16.46 & 100.00 & \\
\hline
\end{tabular}

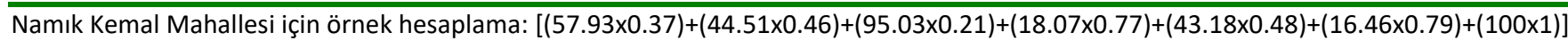

$4.09^{-1}=51.25$

Çizelge 6. Aktif yeşil alan olanakları seti endeksi (AYAOSE) değerleri

\begin{tabular}{lccc}
\hline Mahalleler & & (Ortalama Endeks Değerleri)/En Yüksek Endeks Değeri).100 = AYAOSE \\
\hline Barbaros & 50.96 & 87.97 & 57.93 \\
Cevatpaşa & 39.16 & 87.97 & 44.51 \\
Esenler & 83.60 & 87.97 & 95.03 \\
Kemalpaşa & 15.90 & 87.97 & 18.07 \\
İsmetpaşa & 37.98 & 87.97 & 43.18 \\
Fevzipaşa & 14.48 & 87.97 & 16.46 \\
Namık Kemal & 87.97 & 87.97 & 100.00 \\
\hline
\end{tabular}

Çizelge 7. Çanakkale kentsel alanında aktif yeşil alan olanakları seti endeksi (AYAOSE) ve verimli aktif yeşil alan olanakları seti (VAYAOS) değerleri

\begin{tabular}{ccc}
\hline Mahalleler & AYAOSE Değerleri & VAYAOS Değerleri \\
\hline Barbaros & $\mathbf{5 7 . 9 3}$ & $\mathbf{5 6 . 4 1}$ \\
Cevatpaşa & 44.51 & 54.22 \\
Esenler & $\mathbf{9 5 . 0 3}$ & $\mathbf{6 5 . 6 2}$ \\
Kemalpaşa & 18.07 & 45.55 \\
İsmetpaşa & 43.18 & 52.50 \\
Fevzipaşa & 16.46 & 45.32 \\
Namık Kemal & $\mathbf{1 0 0 . 0 0}$ & $\mathbf{5 1 . 2 5}$ \\
\hline
\end{tabular}


Yeşil alan endeks değerleri 44.51, 18.07, 43.18, 16.46 olan aynı sırayla Cevatpaşa, Kemalpaşa, İsmetpaşa ve Fevzipaşa Mahallelerinin verimlilik yeşil alan değerlerinin ise, $54.22,45.55$ ve $52.50,45.32$ olarak artış gösterdiği belirlenmiştir (Çizelge 7). Bu durum, bu mahallelerde yaşayan insanların, rekreasyonel gereksinimlerini diğer mahallelerdeki yeşil alan olanaklarıyla karşıladıklarını gösterir niteliktedir. Verimlilik yeşil alan değerlerinin yüksek oluşu da bununla ilişkilendirilebilir. Bir kentteki bölgesel aktif yeşil alanların sayıca ve alanca fazla olmasının verimlilikle ilişkilendirilemeyeceği sonucuna ulaşılabilir. Öyle ki, dağılımında eşitsizlik olan yeşil alanların kent genelinde yararlanma yüzdeleri, mahalle düzeyinde verimlilik aktif yeşil alan değerleri AYAOSE değerlerine göre azalan yönde ise fazla; artan yönde ise az olabilmektedir (Çizelge 7). Sonuç olarak; Çanakkale merkez mahallelerindeki aktif yeșil alan dağılımlarının yeterli ve dengeli olduğundan söz etmek çok doğru görünmemektedir.

Ulusal ve uluslararası benzer yöntemlerle yapılmış çalışmaların sonuçları ile bu çalışmaya özgün sonuçlar arasındaki karşılaştırmalar aşağıda verilmeye çalışıımıştır:

Boyacıgil ve Altunkasa (2009) ile Anonim (2016), çalışmalarında, aktif yeşil alanların mahalleler kapsamında eşit dağılıma sahip olmadığı ve verimlilik oranlarının da buna bağlı olarak değişkenlik arz ettiğine dair elde ettikleri sonuçlar bu çalışma sonuçlarıyla paralellik göstermektedir. Göçer ve ark., (2018), kullanım yoğunluğu ve çeşitliliğine bağlı fiziksel donatıların mekânsal kurgusu üzerine yaptığı çalışmada dış mekan kullanım pratiklerine yönelik model alanlar geliştirmişlerdir. Çalışma, özellikle konfor ve kullanım temelli kamusal yaşam oluşturabilmek için gerekli tasarım ve planlama ölçütlerinin tespiti noktasında bu çalışmayla örtüşmektedir. Giles-Corti ve ark. (2005), Avustralya'nın Perth anakentinde yer alan aktif yeşil alanların büyüklük, konuta yakınlık (yaya ulaşılabilirlik) özelliklerinin kullanıcı üzerindeki etkilerini araştırmışlardır. Aktif yeşil alanlar ile kullanıcılar arasında kullanıma yönelik davranışlar, eğilimler ve yoğunluklar istatistiksel olarak ilișkilendirilmiștir. Ulaşılan bulgulardan kullanım düzeyi ile ulaşılabilirlik arasında bu çalışma sonuçlarıyla da örtüşür nitelik arz eden önemli bir ilişki ortaya çıkmıştır. Gilliland ve ark. (2006), Kanada'nın London kentini hedef alan çalışmasında mahalle düzeyinde aktif yeşil alan dağılımlarının endekslenmesini oyun alanı olanaklarının en fazla olduğu mahalle verilerini kullanarak yapmış olmasından ve oyun alanı gereksinimlerinin oyun alanı yetersizliği ve ekonomik düzeyle sıkıntı ölçeğinde açıklanmasından ortaya çıkan bulgular bu çalışma bulgularıyla da örtüşmektedir. Ancak farklı olarak Gilliland ve ark. (2006), çalışmasında çocuk ve genç nüfus ile aktif yeşil alan olanakları arasındaki ilişkinin sağlık açısından ele alındığı dikkat çekmiştir. Li ve Weng (2007), ABD'nin Indianapolis kentinde CBS ve nüfus verileri kullanılarak yaptığı çalışmada yaşam kalitesini belirlemeye çalışmışlardır. Bunun için çevresel ve ekonomik bileşenlerin ağırıklı ele alındığı görülmüştür. Çevresel ağırlıklı nüfus ve konut yoğunluğu, yeşil alan, su yüzeyleri ve sıcaklık; ekonomik ağırlıklı olarak da ortalama hane halkı geliri, kişi başına gelir, yoksulluk sınırı, konut değeri, konut oda sayısı, işsizlik oranı ve eğitim düzeyini incelemişlerdir. Aktif yeşil alan kapsamında kullanıcıya uzaklık ve kişi başına alanlar bu çalışmanın tersine belirleyici olarak tanımlanmamıştır. Bu çalışma ile paralellik gösteren başka bir uluslararası çalışma da English ve Cordell (1993)' in yaptıkları çalışmadır. Öyle ki çalışmada aktif yeşil alan olanaklarının belirlenmesi, kişi başına ve kullanıcıya uzaklıkları bakımından belirlenen aktif yeşil alanlar ile mümkün olmuştur. Ayrıca çalışma, rekreasyon olanakları bakımından yüksek değerler gösteren yerleşimlerdeki rekreasyon olanaklarındaki verimlilik azalmasının düşük değerlere sahip yerleşimlerden gelen kullanıcılardan kaynaklandığına vurgu yapılması ile de bu çalışma sonuçlarıyla örtüşmektedir. Çalışmanın benzer bir başka yönü de su sporlarına dair olanakların düzeyini belirlemede, göl yüzeyinden kişi başına miktar ile göl kıyısı uzunluğunu dikkate alınmış olmasıdır (English ve Cordell 1993).

\section{SONUÇ}

Çalışmadan Çanakkale merkez mahallelerinde bulunan mahalle parkı, çocuk oyun alanı ve spor alanı gibi aktif yeşil alanların nüfus farklılığı ile miktarından bağımsız planlanması, bu alanlarda toplumsal faydanın azalabileceğini göstermiştir. Çanakkale kentsel alanı, mevcut yapısı itibariyle nitelikli yapılaşmadan ve kentsel yaşam kalitesinden uzaktır. Mevcut durum itibariyle kent merkezinde kişi başına aktif yeşil alan miktarının, (MP, ÇOA ve SA türünde) $2.83 \mathrm{~m}^{2}$ hesaplanmış olması da bunu doğrular niteliktedir. Söz konusu değer yasal değer olan $10 \mathrm{~m}^{-2}$ kişi'den düşüktür (Anonim, 2014b). Kentsel yaşam kalitesindeki artışın bireyin refah düzeyiyle doğru 
orantılı olduğu ve bunun da kent dokusunda planlanan verimli aktif yeşil alan olanaklarıla gerçekleşebileceği düşünülürse, kentlerin değişerek ve gelişerek hızla dönüşüm arz ettiği günümüzde aktif yeşil alanların kullanıcı nüfus niteliklerinin dikkate alınarak planlanması gerekliliği de öne çıkmaktadır. Çalışma aktif yeşil alan kullanıcılarının algı ve düşünceleri ile kullanıcı memnuniyetine yönelik yapılacak farklı çalışmalarla desteklenebilir. Dolayısıyla birbirini destekler nitelikte olan çalışmalar kombinasyonunda kentsel alanda verimliliği yüksek, güvenli, zengin donatılı aktif yeşil alanlar tesis edilebilir (Özdemir, 2019). Bu da kentsel yaşam kalitesini artırmada etkili, bir o kadar da gerekli süreci beraberinde getirecektir.

\section{KAYNAKLAR}

Akpınar A (2019) Kentsel yeşil alanların kalitesinin insan sağlığı ve fiziksel aktivitesi üzerindeki etkisinin incelenmesi, Artvin Çoruh Üniversitesi, Orman Fakültesi Dergisi, 20 (1): 36-46.

Alkan Y, Sağlık A, Kelkit A (2016) Site yerleşimlerinde dış mekân - peyzaj niteliğinin ölçülmesi ve konut değerlerine etkisi üzerine bir araştırma: Çanakkale kenti örneği. Uluslararası Hakemli Tasarım ve Mimarlık Dergisi, 9: 111-128.

Alkan Y, Uslu C (2016) Aktif yeşil alanların konut fiyatları üzerine etkisinin araştırılması: Mersin ili Yenişehir ilçesi örneği, İnönü Üniversitesi, Sanat ve Tasarım Dergisi, 6(13): 1-10.

Alkan Y, Uzun G (2016) Erdemli kenti mücavir alanı içinde ekolojik kapsamlı alan kullanımı üzerine bir araştırma, Akademik Ziraat Dergisi 5(1): 35-50.

Anonim (2010) T.C. Başbakanlık Sosyal Hizmetler ve Çocuk Esirgeme Kurumu, http://www.unicef.org.tr/files/bilgimerkezi/doc/c ocuk-istismari-raporu-tr.pdf, Erişim Tarihi: 28.06.2019.

Anonim (2014a) Bağımsız İnternet Gazetesi Evrensel, Madde bağımlılığında 8 yılda çarpıcı artış, https://www.evrensel.net/haber/89216/maddebagimliliginda-8-yilda-carpici-artis, Yayın Tarihi: 1 Ağustos 2014, Erişim Tarihi: 28.06.2019.

Anonim (2014b) Çevre ve Şehircilik Bakanlı̆̆ı, Mekansal Planlar Yapım Yönetmeliği, http://www.resmigazete.gov.tr/eskiler/2014/06/ 20140614-2.htm Yayın Tarihi: 2014, Erişim Tarihi: 23.04.2019.

Anonim (2016) Kartal Belediyesi, 20 Mahalle 1 Kartal Mahalle Eylem Planı (MEP) https://www.kartal.bel.tr/tr/dosyalar/mep.pdf,
Yayın Tarihi: Haziran 2016, Erişim Tarihi: 28.06.2019.

Anonim (2017a) Türkiye İstatistik Kurumu, çocuk istatistikleri-güvenlik ve adalet, Türkiye' de çocuk istismarı ve aile içi şiddet araştırması, https://biruni.tuik.gov.tr/medas/?kn=204\&locale =tr, Erişim Tarihi: 28.06.2019.

Anonim (2017b) Kültür ve Medeniyet Dergisi, Çocuğun Cinsel Eğitimi/Pedagog Ali Çankırılı, http://www.gonuldergisi.com/cocugun-cinsel-

egitimi-pedagog-ali-cankirili.html, Yayın Tarihi: 30 Aralık 2017, Erişim Tarihi: 28.06.2019.

Anonim (2017c) Balıkesir Bölge Müdürlüğü, 2017 Yılı Adrese Dayalı Nüfus Kayıt Sistemi: Çanakkale.

Anonim (2017d) Çanakkale Uygulama İmar Planı/Harita ve Planlama Birimi/ Çanakkale Belediyesi, 2017.

Anonim (2018) Milli Eğitim Bakanlığı, İstanbul/Esenyurt/Bakyapı İlkokulu, çocuk istismarı ve inmali, http://bakyapiilkokulu.meb.k12.tr/tema/ Erişim Tarihi: 28.06.2019.

Bolund P, Hunhammar S (1999) Ecosystems services in urban areas. Ecological Economics 29: 293-301.

Boyacigil O, Altunkasa MF (2009) Adana kuzeybatı üst kentsel gelişme alanı örneğinde verimli aktif yeşil alan olanaklarının belirlenmesi, Akdeniz Üniversitesi Ziraat Fakültesi Dergisi, 22(1), 59- 67.

Brown LR, Flavin C, Postel S (1998) Gezegenimizi kurtarmak: Küresel Ekonominin Çevresel Olarak Sürdürülebilirliği (Çeviren S. Gül) Tübitak-Tema Vakfı Yayınları (4) Ankara.

Cohen M (1996) Habitat ii and the challenge of the urban environment: Bringing Together The Two Definitions of Habitat. International Social Science Journal, 1996: 95-101.

Çukurçayır MA (2002) Siyasal katılma ve yerel demokrasi, Konya: Çizgi Kitabevi, 99s.

English DBK, Cordell HK (1993) Effective recreation opportunity set. (eros) index: A computable measure of recreation supply. U.S. Department of Agriculture Forest Service, Research Paper, Asheville, North Carolina.

Gangloff D (1996) The Sustainable City. American Forests 101 (5-6), pp. 30-36.

Geray C (1998) Kentsel yaşam kalitesi ve belediyeler. Türk İdare Dergisi (421):326-341.

Giles-Corti B, Broomhall MH, Knuiman M, Collins C, Douglas K, Ng K, Donovan RJ (2005) Increasing walking: how important is distance to, attractiveness, and size of public open space? 
American Journal of Preventive Medicine, 28(2S2), 169-176.

Gilliland J, Holmes M, Irwin JD, Tucker P (2006) Environmental, equity is child's play: mapping public provision of recreation opportunities in urban neighbourhoods. Vulnerable children and youth studies. December 2006, 1(3): 256-268.

Göçer Ö, Torun AÖ, Bakoviç M (2018) Thermal comfort, behavioral mapping and space syntax analysis of outdoor spaces in a suburban campus, Journal of the Faculty of Engineering and Architecture of Gazi University, $33: 3$ (2018): 853873.

Jim CY (2004) Green-space preservation and allocation for sustainable greening of compact cities. Cities, 21(4): 311-320.

Külekçi EA, Irmak MA (2019) Kent Parklarında Kullanılan Donatı Elemanlarının Estetik ve Fonksiyonel Açıdan Yeterlilikleri; Erzurum Kenti Örneği. Journal of the Institute of Science and Technology, 9(2): 1144-1155.
Li G, Weng Q (2007) Measuring the quality of life in city of indianapolis by integration of remote sensing and census data. International Journal of Remote Sensing, 28 (2): 249-267.

Özdemir A (2019) Katılımcı Planlama İçin Yöntem Yaklaşımı: Sakarya Mahallesi Parkı Örneği, DenizliTürkiye. Journal of the Institute of Science and Technology, 9 (1): 233-243.

Payne S (2009) Open space: People space, Journal of Environmental Psychology, 29: 532-533.

Sağlık A, Alkan Y, Kelkit A, Devecioğlu, NE, Sağlık E (2016) Meydanların kent kimliği üzerine etkileri: Çanakkale iskele meydanı", Uluslararası Hakemli Tasarım ve Mimarlık Dergisi, (7): 1-12.

Torunoğlu E (1997) Kentleşme çevre sorunları ve kentsel yaşam kalitesi ve kirlendi dünya. Öteki Matbaası, Ankara.

Willis KG, Turner RK, Bateman IJ (2001) Urban planning and management. Edward Elgar Publishing, New York. 